\title{
Real-time ultrasound-guided retrobulbar block vs blind technique for cataract surgery (pilot study)
}

This article was published in the following Dove Press journal: Local and Regional Anesthesia

\author{
Ahmed Zaghloul Foad' \\ Mohammed Ahmed \\ Mansour ${ }^{2}$ \\ Mahmoud Badry Ahmed' \\ Hany R Elgamal',3 \\ Hany Elmekawey \\ Elmekawey Ibrahim ${ }^{4}$ \\ Abdelraheem Elawamy ${ }^{5}$ \\ 'Kasr Alainy, Cairo University, Haram, \\ Giza, Egypt; ${ }^{2}$ Kasr Alainy, Cairo \\ University, Nasr City, Cairo, Egypt; \\ ${ }^{3}$ Kasralainycairo University, Elmariotia, \\ Haram, Giza, Egypt; ${ }^{4}$ Kasralainycairo \\ University, Elharam, Giza, Egypt; \\ ${ }^{5}$ Asiout University, Asyut, Egypt
}

Correspondence: Mahmoud Badry Ahmed

Kasralainycairo University, 55 Tersast,

Haram, Giza, Egypt

Tel +20 I0 01844291

Emailmahmoud_badry2000@yahoo.com
Background: Retrobulbar regional eye block aims to ensure eye globe akinesia and anesthesia during ophthalmic surgery, and despite the rarity of occurrence of complications due to the blind needle passage while performing either peribulbar or retrobulbar block, some of them are serious and may be life threatening.

Aim: The aim of this study was to estimate the accuracy and safety of real-time ultrasound-guided retrobulbar regional anesthesia in comparison with the blind technique for cataract surgery.

Design: This was a prospective randomized controlled trial.

Methodology: A total of 30 patients who met the inclusion criteria were registered in our research and were divided into two groups: 15 patients received real-time ultrasound-guided retrobulbar block compared to 15 patients who received the block using the blind technique.

Results: One patient out of the 30 was excluded from the analysis, and no statistically significant differences were observed between the two groups regarding the onset of akinesia, numeric pain rating scores, rate of complications, and degree of patient and physician satisfaction.

Conclusion: There were no statistically significant difference between real-time ultrasoundguided and blind retrobulbar regional eye blocks concerning the onset of action, total volume of injected local anesthetic solution, supplemental injection required, pain scores, and degree of patient satisfaction.

Keywords: ultrasound, retrobulbar block, cataract, prospective observational study

\section{Introduction}

Ophthalmic operation is considered one of the commonest operative procedures demanding anesthesia worldwide. ${ }^{1}$ The two main approaches to the eye with surgical and medical conditions that can be provided for intraocular surgeries, especially for elderly patients, are retrobulbar and peribulbar blocks. ${ }^{2}$ Cataract surgery indeed demands strong blockade of the motor nerve supply of eye globe and eye lids. ${ }^{3}$ Retrobulbar block provides rapid onset anesthetic solution with akinesia and adequate control of intraocular pressure. ${ }^{4}$ Peribulbar regional eye block like the retrobulbar technique aims to ensure eye globe akinesia and anesthesia during ophthalmic operation and is supposed to be safer than retrobulbar block. ${ }^{5,6}$ However, it was reported that there is no proof of variance concerning the efficacy and safety profiles between the two approaches. ${ }^{7}$ Despite the rarity of occurrence of complications due to the blind needle passage while performing either peribulbar or retrobulbar block, some of them are serious and may be life threatening. ${ }^{8}$ Perforations of the globe, ${ }^{9,10}$ damage to the optic nerve, ${ }^{11}$ and possibly lethal sequel of local anesthetic agents on the central nervous system $^{12-14}$ are described in the literature. 
As optic nerve diameter can be easily visualized using ultrasound (US), we postulated that US-guided retrobulbar injection of local anesthesia should amend the accuracy and safety of retrobulbar regional eye block through real-time visualization of the needle placement near to the optic nerve.

Our aim was to evaluate the quality and safety of real-time US-guided retrobulbar regional anesthesia in comparison with the blind technique for cataract surgery as we postulated that direct visualization of the optic nerve and the introduced blocking needle might fasten the onset of akinesia and decrease the risk of complications. Our aim was to evaluate the quality of real-time US-guided retrobulbar regional anesthesia in comparison with the blind technique for cataract surgery as we postulated that direct visualization of the optic nerve and the introduced blocking needle might fasten the onset of akinesia and decrease the risk of complications.

\section{Methodology}

This prospective observational study was conducted in the Ophthalmology Department, Cairo University Hospitals in all mechanically ventilated patients. This study was approved by the Kasralainy Cairo University Ethical Committee, and written informed consent was obtained from all subjects participating in the trial. The trial was registered prior to patient enrollment at clinicaltrials.gov (PACTR201803003158311, date of registration: March 27, 2018). Patients in the age group of 40-70 years with American Society of Anaesthesiologists classification I, II, and III scheduled for elective cataract surgery under regional anesthesia were included in the study and randomly assigned using opaque sealed envelope after enrolment into two groups, US group (group $\mathrm{A}, \mathrm{n}=14$ ) and conventional group (group $\mathrm{B}, \mathrm{n}=15$ ). Numbers in the envelope were generated by a computer-generated randomization (www.randomization.com).

Uncooperative patients and those with axial length $>28$ $\mathrm{mm}$, posterior staphyloma, complicated vitreous hemorrhage, or contraindications to local anesthesia were excluded.

Preparation of all patients:

- On the day of surgery, all patients were familiarized with the Numeric Pain Rating scale (NPR). ${ }^{15}$

- After assuring fasting and consent, intravenous access was secured.

- In the operating room, patients' heart rate, arterial blood pressure, oxygen saturation, and electrocardiogram were monitored.

- Supplemental oxygen (2-3 L/min) via nasal prongs was connected to all patients.

\section{Technique}

US group (group A)

The US machine used in the study was Siemens ${ }^{\circledR}$ ACUSON X600 ${ }^{\mathrm{TM}}$ Ultrasound System. Phased array US transducer (6 $\mathrm{MHz}$ ) was used to guide needle insertion. The probe and the cable were wrapped in a sterile cover. The gel in contact with the skin was sterile. The skin was disinfected before any contact with the probe and the needle. The probe was applied on the outer quadrant of the upper eye lid of a closed eye vertically with slight lateral probe angulation (around $10^{\circ}-15^{\circ}$ ) with marker directed caudally, and the probe was held between the index and thump fingers with the index placed on the lower eye lid in such way pushing the globe upwards; then the needle was introduced at the lower outer quadrant of the orbit in line with the probe and advanced perpendicularly until the tip of the needle reached the equator of the globe. Then, it was directed and advanced close to the optic nerve. Once the needle was placed in the point we need (few millimeters from the nerve), the probe was removed and a bolus of $4 \mathrm{~mL}$ of the local anesthetic solution (Lidocaine 1\%) was injected.

Time of application of the US transducer on the upper eye lid was minimized targeting not to exceed 1 minute.

\section{Conventional group (group B)}

Ideal aseptic precautions were taken; then the needle with the vision fixed straight ahead in the neutral position was introduced. The entry point was identified by the feeling of the infra orbital groove by the left index finger, simultaneously; the finger was also used to push the globe slightly and gently upwards, The needle was introduced to a depth of 20-25 mm, with the bevel of the needle being cephalically directed toward the globe. The patients were then requested to look right, left, up, and down to make sure that the eyeball was moving clearly and not penetrated by the needle. After negative aspiration, $4 \mathrm{~mL}$ of local anesthetic solution (Lidocaine 1\%) was then injected.

In the two groups, just next to injection, gentle digital massage was applied for 5-10 minutes to the closed eye to promote the spread of the local anesthetic and to soften the globe. Digital pressure was released every 30 seconds for 5-10 seconds to allow for the vascular pulsations to occur. Evaluation of the motor block including globe akinesia (globe movement in all directions by the four recti muscles) was done every 30 seconds after 2 minutes of injection by asking the patient to look upwards, downwards, medial, and lateral.

Supplemental injection was given when globe akinesia was absent in two or more directions after 4 minutes of the first injection, and it was done in the medial canthus using 
the same needle that was inserted in the blind pit between the caruncle and the medial canthus, and directed straight back parallel to the medial orbital wall with the bevel of the needle directed toward the globe. The needle was inserted to a depth of 15-20 mm. After negative aspiration, another volume of local anesthetic mixture $(2 \mathrm{~mL})$ was injected.

\section{Primary outcomes were onset of akinesia of the globe}

The primary outcomes were degree of pain experienced during surgery and measured using an NPR (1-10), degree of patient satisfaction, the need for supplemental injection with local anesthetic solution, and occurrence of complications that were classified into local complications (examples include retrobulbar hemorrhage, globe perforation, optic nerve damage, and increased intra-ocular pressure) and systemic complications (examples include respiratory depression and cardiopulmonary arrest).

Onset of globe akinesia, NPR scale 1 hour postoperatively, the degree of satisfaction of patients and surgeons, and the occurrence of either local or systemic complications were recorded.

Both the patient and the surgeon were asked to fill in the satisfaction questionnaire which for simplicity relied on a simple questionnaire for patient rating satisfaction as ( 1 is very satisfied, 2 moderately satisfied, and 3 poorly satisfied), and surgeon satisfaction assessment will be by a satisfied or not satisfied questionnaire.

\section{Sample size calculation}

Sample size calculation was done using the comparison of onset of akinesia of the globe between cases undergoing cataract operations treated with US-guided retrobulbar block and those treated with conventional blind technique. As reported in previous publication, ${ }^{16}$ the mean $\pm \mathrm{SD}$ of onset of globe akinesia in conventional blind technique was $\sim 6.9 \pm 0.9$ minutes, and we assumed that the minimal clinically important difference is $20 \%$ shortening of this time by using the US guide. Accordingly, we calculated that the minimum proper sample size was 12 cases in each arm (so we included 15 patients in each group to compensate for dropout) to achieve 95\% power at $\alpha=0.05$ level using Student's $t$-test for independent samples. Sample size calculation was done using Stats Direct statistical software version 2.7.2 for MS Windows (Stats Direct Ltd., Cheshire, UK).

\section{Statistical analysis}

Data will be statistically described in terms of mean $\pm \mathrm{SD}$, median and range, or frequencies (number of cases) and percentages when appropriate. Comparison of numerical variables between the study groups was done using Student's $t$-test for independent samples in comparing two groups when normally distributed and Mann-Whitney $U$ test for independent samples when not normally distributed. For comparing categorical data, chi-squared test was performed. Exact test was used instead when the expected frequency was $<5$. A probability value ( $P$-value) $<0.05$ was considered statistically significant. All statistical calculations were done using computer programs Microsoft Excel 2007 (Microsoft Corporation, Redmond, WA, USA) and SPSS (SPSS Inc., Chicago, IL, USA) version 15 for Microsoft Windows.

\section{Results}

A total of 30 patients fulfilling inclusion criteria were enrolled in our study; their recruitment and group allocation are shown in Figure 1, of whom one patient was excluded from the analysis after observing the needle piercing the globe which was withdrawn immediately and the case postponed. Baseline demographic and physiologic data are shown in Table 1.

There was no statistically significance difference between the two groups regarding the onset of akinesia, total volume injected of local anesthetic, supplemental injection required, and pain score as shown in Table 2 .

No systemic complications were encountered in both the groups, and no statistically significant difference was detected regarding local complications as shown in Table 3. Moreover, there was no statistically significant difference between the US and the conventional groups with regard to the patients' and physician's satisfaction.

\section{Discussion}

We found that there was no significant difference between the two groups regarding the onset of action, total volume of injected local anesthetic solution, supplemental injection required, and pain score.

It was stated that US guidance allows real-time visualization of needle advancement and local anesthetic spread of the injectate during the performance of retrobulbar block; ${ }^{17}$ so we were expecting that performance of the block under US guidance could improve the quality and safety of the block; however, the results did not show significant difference between this technique and the blind one which may be because of the small sample size which is the main limitation of this study, and on the other hand, the anesthesiologist who did the blocks was well trained and expert in performing the blind technique. 


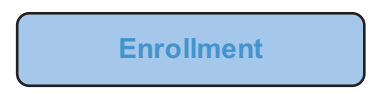

Assessed for eligibility $(n=47)$

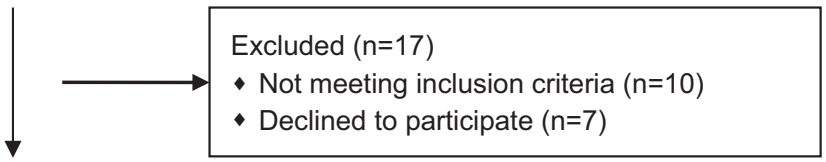

Randomized $(\mathrm{N}=30)$
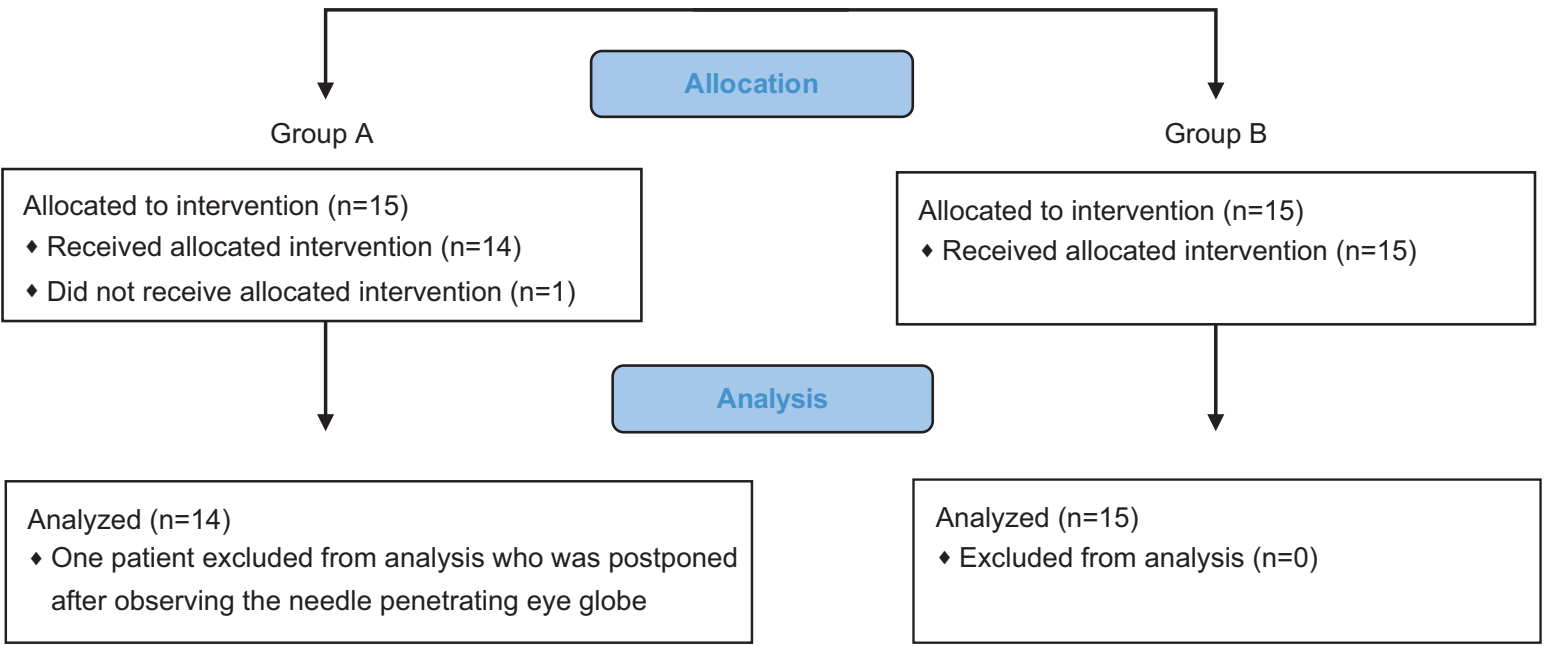

Figure I Patient flowchart.

Table I Age, sex and axial length

\begin{tabular}{|l|l|l|l|}
\hline Parameter & $\begin{array}{l}\text { Group A } \\
(\mathbf{n = 1 4 )}\end{array}$ & $\begin{array}{l}\text { Group B } \\
(\mathbf{n = 1 5 )}\end{array}$ & P-value \\
\hline Age (years) & $58.2 \pm 8.1$ & $59.5 \pm 8.1$ & 0.6712 \\
\hline Sex & & & \\
$\quad$ Male & $60 \%$ & $53 \%$ & 0.7513 \\
$\quad$ Female & $40 \%$ & $47 \%$ & \\
\hline Axial length (mm) & $24.1 \pm 1.5$ & $24.5 \pm 1.9$ & 0.5435 \\
\hline
\end{tabular}

Note: Data are expressed as mean \pm SD and percentage.

Table 2 Onset of action, total volume injected, augmentation required and NPR score

\begin{tabular}{|l|l|l|l|}
\hline Parameter & $\begin{array}{l}\text { Group A } \\
(\mathbf{n = 1 4 )}\end{array}$ & $\begin{array}{l}\text { Group B } \\
(\mathbf{n = 1 5 )}\end{array}$ & P-value \\
\hline Onset of action $(\mathrm{min})$ & $4.5 \pm 0.8$ & $4.7 \pm 1.2$ & 0.5469 \\
\hline Total volume injected $(\mathrm{mL})$ & $4.2 \pm 1.5$ & $4.5 \pm 0.9$ & 0.8438 \\
\hline Augmentation required $(\%)$ & $3(20 \%)$ & $4(27 \%)$ & 0.7712 \\
\hline NPR score & $\mathrm{I}(\mathrm{I})$ & $\mathrm{I}(\mathrm{I})$ & 0.9604 \\
\hline
\end{tabular}

Note: Data expressed as mean $\pm S D$ and percentage.

Abbreviation: NPR, numeric pain rating score.

In 1995, Birch et a ${ }^{18}$ described the use of US to localize the tips of retrobulbar needles during retrobulbar block and concluded that needle tips are closer to the eye globe than previously thought and advised that the use of external
Table 3 Total complications, perforation, ecchymosis and subconjunctival Hge

\begin{tabular}{|l|l|l|l|}
\hline Parameter & $\begin{array}{l}\text { Group A } \\
(\mathbf{n = 1 4 )}\end{array}$ & $\begin{array}{l}\text { Group B } \\
(\mathbf{n = 1 5 )}\end{array}$ & P-value \\
\hline Total complications & $2(13 \%)$ & $2(13 \%)$ & \\
Perforation & $\mathrm{I}(6.5 \%)$ & 0 & \\
Ecchymosis & $\mathrm{I}(6.5 \%)$ & $\mathrm{I}(6.5 \%)$ & \\
Subconjunctival Hge & 0 & $\mathrm{I}(6.5 \%)$ & \\
\hline
\end{tabular}

Note: Data are expressed as percentage. Abbreviation: Hge, hemorrhage.

anatomic landmarks alone during regional anesthetic block might be insufficient.

In 2008, Luyet et al ${ }^{19}$ conducted their new US-guided retrobulbar technique on 20 cadavers aiming to improve safety and efficacy of the procedure by direct identification of the needle position close to optic nerve.

To the best of our knowledge, no study has compared the real-time US-guided retrobulbar block with the blind technique which make it difficult to compare our results with others.

Recently, Najman et al ${ }^{20}$ tried to estimate the accuracy and safety of periconal regional eye blockade under US guidance compared to blind technique and found that 
there were no differences in corneal pain, eye movement, or the occurrence of the rate of complications between the two groups. These results are in line with our findings as we did not detect any significant differences between the patients who received retrobulbar block guided with US and those who received the block blindly, with respect to all the measured parameters including the rate of complications; however, in the US group, we noticed the needle piercing the globe in one patient (who performed a sudden movement during the introduction of the blocking needle) in whom the needle was withdrawn without injecting the local anesthetic solution which may be considered as an advantage to the use of US that enabled us to see the needle inside the globe and that prevented the occurrence of more catastrophic complication.

We think that US guidance had helped us during the performance of the block through direct visualization of needle trajectory and spread of injected local anesthetic; however, we found no difference between the two block techniques which may be because of the small sample size and that the anesthesiologist who did the blocks was well trained and expert in performing the blind retrobulbar technique.

The most important limitation we faced was the unavailability of high-frequency transducer of small size so we used the lower frequency phased array probe as its size could fit with the globe and allowed space for needle insertion.

We suggest that the use of US to perform a sub-Tenon's block will help in reducing the risk of sight-threatening or life-threatening complications, and investigations in this field are recommended.

\section{Conclusion}

There was no statistical significant difference between real time US guided and blind retro-bulbar regional eye blocks regarding onset of action, total volume of injected local anesthetic solution, supplemental injection required, pain scores, and degree of patient's satisfaction.

\section{Author contributions}

Zaghloul Foad was the principle investigator and responsible for the idea, the technique, and the paper writing and revision. Badry Ahmed was responsible for data collection, plagiarism revision, clinical trial registry number, editing, and the corresponding author of this publication. Elgamal was responsible for data analysis, consent of the patient, results revision, tables, and figures. Mansour and Elawamy were responsible for data collection and analysis. Elmekawey
Ibrahim was the ophthalmologist responsible for the complications of the technique and data collection. All authors contributed to data analysis, drafting or revising the article, gave final approval of the version to be published, and agree to be accountable for all aspects of the work.

\section{Disclosure}

The authors report no conflicts of interest in this work.

\section{References}

1. Leaming DV. Practice styles and preferences of ASCRS members-2003 survey. J Cataract Refract Surg. 2004;30(4):892-900.

2. Hamilton RC, Gimbel HV, Strunin L. Regional anaesthesia for 12,000 cataract extraction and intraocular lens implantation procedures. Can J Anaesth. 1988;35(6):615-623.

3. Ripart J, Lefrant JY, de La Coussaye JE , Prat-Pradal D, Vivien B, Eledjam JJ. Peribulbar versus retrobulbar anesthesia for ophthalmic surgery: an anatomical comparison of extraconal and intraconal injections. Anesthesiology. 2001;94(1):56-62.

4. Ali-Melkkilä TM, Virkkilä M, Jyrkkiö H. Regional anesthesia for cataract surgery: comparison of retrobulbar and peribulbar techniques. Reg Anesth. 1992;17(4):48-49.

5. Davis DB, Mandel MR. Posterior peribulbar anesthesia: an alternative to retrobulbar anesthesia. J Cataract Refract Surg. 1986;12(2):182-184.

6. Murdoch IE. Peribulbar versus retrobulbar anaesthesia. Eye. 1990;4(Pt 3):445-449.

7. Alhassan MB, Kyari F, Ejere HO. Peribulbar versus retrobulbar anaesthesia for cataract surgery. Cochrane Database Syst Rev. 2015 (7):CD004083.

8. Davis DB, Mandel MR. Efficacy and complication rate of 16,224 consecutive peribulbar blocks. A prospective multicenter study. J Cataract Refract Surg. 1994;20(3):263.

9. Wearne MJ, Flaxel CJ, Gray P, Sullivan PM, Cooling RJ. Vitreoretinal surgery after inadvertent globe penetration during local ocular anesthesia. Ophthalmology. 1998;105(2):371-376.

10. Ramsay RC, Knobloch WH. Ocular perforation following retrobulbar anesthesia for retinal detachment surgery. Am J Ophthalmol. 1978;86(1):61-64.

11. Pautler SE, Grizzard WS, Thompson LN, Wing GL. Blindness from retrobulbar injection into the optic nerve. Ophthalmic Surg. 1986;17(6):334-337.

12. Javitt JC, Addiego R, Friedberg HL, Libonati MM, Leahy JJ. Brain stem anesthesia after retrobulbar block. Ophthalmology. 1987;94(6):718-724.

13. Brookshire GL, Gleitsmann KY, Schenk EC. Life-threatening complication of retrobulbar block. A hypothesis. Ophthalmology. 1986;93(11):1476-1478.

14. Rosenblatt RM, May DR, Barsoumian K. Cardiopulmonary arrest after retrobular block. Am J Ophthalmol. 1980;90(3):425-427.

15. McCaffery M, Pasero C. Pain: Clinical Manual. St. Louis; 1999:16.

16. Eghbal MH, Tabei H, Taregh SA, Razeghinejad MR. The effect of addition of low dose atracurium to local anesthetic in retrobulbar block for cataract surgery. Middle East J Anaesthesiol. 2010;20(4):535-538.

17. Palte HD. Ophthalmic regional blocks: management, challenges, and solutions. Local Reg Anesth. 2015;8:57-70.

18. Birch AA, Evans M, Redembo E. The ultrasonic localization of retrobulbar needles during retrobulbar block. Ophthalmology. 1995;102(5):824-826.

19. Luyet C, Eichenberger U, Moriggl B, Remonda L, Greif R. Real-time visualization of ultrasound-guided retrobulbar blockade: an imaging study. Br J Anaesth. 2008;101(6):855-859.

20. Najman IE, Meirelles R, Ramos LB, Guimarães TC, do Nascimento P. A randomised controlled trial of periconal eye blockade with or without ultrasound guidance. Anaesthesia. 2015;70(5):571-576. 


\section{Publish your work in this journal}

Local and Regional Anesthesia is an international, peer-reviewed, open access journal publishing on the development, pharmacology, delivery and targeting and clinical use of local and regional anesthetics and analgesics. The journal is included in PubMed, and welcomes submitted papers covering original research, basic science, clinical studies, reviews and evaluations, guidelines, expert opinion and commentary, case reports and extended reports. The manuscript management system is completely online and includes a very quick and fair peer-review system, which is all easy to use. Visit http://www.dovepress.com/ testimonials.php to read real quotes from published authors. 